\title{
BIBLIOTERAPIA: O QUIASMA ENTRE AS CIÊNCIAS
}

\section{LA BIBLIOTERAPIA: EL QUIASMA DE LAS CIENCIAS}

\author{
Carla Sousa* \\ Clarice Fortkamp Caldin**
}

\section{RESUMO:}

Introdução: No presente artigo apresenta-se a Biblioterapia, entendida como a função terapêutica da leitura, como interlocução entre Ciência da Informação, Filosofia e Psicologia. Parte-se do conceito de interdisciplinaridade, próprio das ciências pósmodernas, que fortalece a compreensão do ser humano na complexa sociedade do Conhecimento.

Objetivo: Apresentar o entrelaçamento da Ciência da Informação, Filosofia e Psicologia no tocante a conceitos e ideias sobre a Biblioterapia.

Metodologia: A pesquisa foi exploratória, qualitativa e bibliográfica. A revisão de literatura apontou os primeiros estudos em Ciência da Informação; apresentou a Biblioterapia com foco no interagente; mostrou as possibilidades de cruzamento entre a Ciência da Informação, Filosofia e Psicologia sob o viés da Biblioterapia.

Resultados: A quebra de paradigmas em Ciência da Informação - primazia dos fatores econômicos e tecnológicos - e a inserção do interagente como fim primeiro e último das preocupações, têm permitido estudos voltados para o ser humano como personagem central do processo informacional.

Conclusões: O compartilhamento de ideias entre a Ciência da Informação, Filosofia e Psicologia permite um entendimento mais acurado da Biblioterapia em especial sobre: diálogo, Inter corporeidade, intersubjetividade, catarse.

Palavras-chave: Biblioterapia. Ciência da Informação. Interdisciplinaridade. Filosofia. Psicologia.

*Mestranda do Programa de Pós-Graduação em Ciência da Informação da Universidade Federal de Santa Catarina - UFSC. E-mail: carla_sou@hotmail.com.

**Doutora em Literatura pela Universidade Federal de Santa Catarina (UFSC). Professora do Programa de Pós-Graduação em Ciência da Informação da Universidade Federal de Santa Catarina - UFSC. E-mail: claricefcaldin@hotmail.com. 


\section{INTRODUÇÃO}

Ciência (conhecimento demonstrativo) e informação (dados que formam sentido) fazem parte da existência do homem - nascem com e para o ser humano facilitar a vida, adequar-se a novas situações, buscar respostas às suas indagações, viver em sociedade, na constante procura (desde os gregos) do bem e do bom.

A atual Sociedade da informação (que lida com a explosão de dados cujos sentidos são, às vezes, ambíguos), também chamada de Sociedade do Conhecimento (saber lidar com essas ambiguidades), passa por problemas de ordem econômica, social, tecnológica, próprios da Pós-Modernidade.

Como toda e qualquer ciência, para não perecer, a Ciência da Informação não pode ficar restrita aos modelos tradicionais. A natureza autocorretiva das ciências impõe inovações constantes, verificações sistemáticas, estudos cumulativos e excludentes.

Dessa feita, a Ciência da Informação, inicialmente restrita à Biblioteconomia, Museologia, Documentação e ao Jornalismo (LE COADIC, 2004), tem de se adequar aos desafios da interdisciplinaridade, que se coaduna com o movimento da Pós-Modernidade - o quiasma, o entrelaçamento entre as ciências.

Assim é que a Biblioterapia (função terapêutica da leitura) adentra em outros universos informacionais, entre eles, a Filosofia e a Psicologia.

O presente artigo aponta os primeiros estudos em Ciência da Informação, apresenta a Biblioterapia com foco no interagente (ator no processo de comunicação e criação de conhecimento). Além disso, mostra o cruzamento possível da Biblioterapia na Ciência da Informação, Filosofia e Psicologia.

\section{A CIÊNCIA DA INFORMAÇÃO: DESENVOLVIMENTO E COMPLEXIDADE}

A Ciência da Informação nasce num contexto em que a sociedade passa a produzir e consumir informações numa proporção muito grande - o que 
exigiu uma ciência capaz de entender e otimizar todo o processo de acumulação e transmissão da informação para a geração de conhecimento.

Desde o início os estudos em Ciência da Informação enfatizavam o processo em si levando em consideração o caráter interdisciplinar desse novo campo de investigação. Isso porque o objeto de estudo dessa ciência está presente em todas as áreas do conhecimento e necessita de uma junção de esforços para melhor compreendê-lo.

Foi Borko quem primeiro apontou o caráter interdisciplinar da Ciência da Informação, pois, segundo ele, essa nova ciência apresentava componentes tanto das ciências puras quanto das ciências aplicadas. Em 1968 Borko escreve sobre o tema e começa a delinear uma definição para essa nova ciência que vai tomando forma, inicialmente nos Estados Unidos para depois se expandir internacionalmente. Para Borko (1968, p. 3), a Ciência da Informação está ligada ao corpo de conhecimentos relativos à origem, coleta, organização, estocagem, recuperação, interpretação, transmissão, transformação e uso de informação.

Saracevic (1996, p. 47) aponta como áreas de concentração de problemas para a pesquisa e a prática profissional na Ciência da Informação: efetividade, comunicação humana, conhecimento, registros do conhecimento, informação, necessidades de informação, usos da informação, contexto social, contexto institucional, contexto individual e tecnologia da informação. Com base nesse conjunto de temas, o autor afirma que:

Pela sua própria natureza, essas são áreas-problema altamente complexas e, como todos os problemas complexos são tratados de várias formas em muitos campos (assim como o são os problemas relacionados com a energia, matéria, vida, etc). Então, pelo imperativo dos problemas propostos, a $\mathrm{Cl}$ é um campo interdisciplinar (SARACEVIC, 1996, p. 48)

Tal complexidade dos temas é reflexo da sociedade onde nasce a Ciência da Informação. Uma sociedade de difícil compreensão e definição. A discussão Sociedade da Informação versus Sociedade do Conhecimento (sempre presente no campo da Ciência da Informação) vem reforçar esse ponto de vista. Ainda não há um consenso entre os teóricos sobre como 
conceituar o momento atual, em que a informação atua como personagem central.

Segundo Burch (2005, p. 3) a ideia de Sociedade do Conhecimento é empregada no meio acadêmico como uma alternativa para Sociedade da Informação. No entanto, a autora aponta que na visão da Unesco o termo mais adequado para o momento atual seria o de Sociedade do Conhecimento, na medida em que "busca incorporar uma concepção mais integral, não ligada apenas à dimensão econômica".

A Sociedade da Informação é a pedra angular das sociedades do conhecimento. O conceito de "sociedade da informação", a meu ver, está relacionado à idéia [sic] da "inovação tecnológica", enquanto o conceito de "sociedades do conhecimento" inclui uma dimensão de transformação social, cultural, econômica, política e institucional, assim como uma perspectiva mais pluralista e de desenvolvimento. $\mathrm{O}$ conceito de "sociedades do conhecimento" é preferível ao da "sociedade da informação" já que expressa melhor a complexidade e o dinamismo das mudanças que estão ocorrendo.[...] o conhecimento em questão não só é importante para o crescimento econômico, mas também para fortalecer e desenvolver todos os setores da sociedade (KHAN apud BURCH, 2005, p. 3)

Esse ponto de vista mais abrangente coloca a Ciência da Informação numa outra perspectiva, ainda mais complexa em seus estudos e pesquisas do que aquela apontada por Borko (1968) ou mesmo Saracevic (1996), pois engloba fatores que estão além dos econômicos e tecnológicos para incluir uma dimensão mais social e humana.

Nesse sentido, faz-se necessário chamar a atenção para o fato de que a Ciência da Informação é entendida, sobretudo, como uma Ciência Social. Le Coadic (2004, p. 19), por exemplo, afirma que as pesquisas nessa área nascem para responder a um problema social concreto. Estando dentro do campo da Ciência Social é impossível perder de vista as questões referentes ao homem e à sociedade dentro do contexto informacional.

No entanto, Araújo (2003) aponta que em termos propriamente teóricoepistemológicos essa inserção (da Ciência da Informação na Ciência Social) não é exatamente óbvia. Nesse contexto, o autor afirma: 
Um suporte teórico fundamental nesse movimento é exatamente o trabalho de Berger \& Luckmann. Ao discutir a realidade como algo que é construído socialmente e não com uma existência em si mesma, independentemente dos sujeitos que conhecem, os autores abrem caminho para uma compreensão da informação não como um dado, uma coisa que teria um significado e uma importância per se, mas como um processo, como algo que vai ser percebido e compreendido de variadas formas de acordo com os sujeitos que estão em relação - o que vai na contramão tanto da definição de Borko (1968) sobre o comportamento e o fluxo da informação excluindo os sujeitos, quanto da definição de Buckland (1991), que vê "a informação como coisa" (ARAÚJO, 2003, p.25).

Tal afirmação aponta para uma visão mais abrangente do conceito da informação e do sujeito que está presente e que contribui de forma ativa em todo o processo de troca de informação e construção de conhecimento. Esse é um ponto de vista que começa a surgir dentro da Ciência da Informação, na tentativa de empoderar o indivíduo, que é, sem dúvida, o personagem central do processo informacional em detrimento do dado ou da informação em si.

Nesse sentido, Le Coadic (2004) considera o indivíduo como foco do processo informacional dentro do que ele denomina o paradigma do usuário. Para o autor, a orientação dos profissionais que atuam no campo da Ciência da Informação tende a sair do documento para a informação e do sistema para o usuário.

No âmbito desse novo paradigma, um centro de documentação ou serviço de Rede 'orientada para o usuário' ressalta explicitamente as necessidades de informação dele, e todas as decisões são tomadas num quadro institucional que o coloca em posição central, sejam elas relativas ao planejamento, às atividades ou gestão. (LE COADIC, 2004, p.110)

Partindo desse pressuposto do indivíduo como foco da Ciência da Informação, é interessante observar que há autores que estão preocupados em trazer essa discussão à tona, a exemplo de Corrêa (2014). A autora propõe, inclusive, uma nova terminologia para melhor definir o sujeito que, atualmente, participa de forma muito mais ativa no processo informacional, deixando de ser mero espectador ou usuário para se tornar um interagente.

Segundo Corrêa (2014), interagente seria a definição mais adequada para o sujeito que utiliza os serviços de informação, seja numa biblioteca, 
arquivo ou centro de documentação, pois ele é um ser participativo que interage no processo.

O fator 'interação', portanto, não deve ser desprezado e indica a possibilidade de uma mudança de foco na maneira de conceituar esse ator extremamente importante para a Ciência da Informação e para a Biblioteconomia, o qual tem recebido uma denominação que reduz significativamente a importância de sua participação nos processos de comunicação e geração de conhecimentos a partir do acesso e apropriação de informações dentro ou fora do ambiente das bibliotecas (CORRÊAA, 2014, p.31, grifo da autora).

A partir da adoção desse novo termo Corrêa (2014, p. 37) aponta para uma questão de mudança cultural. Segundo ela, é preciso mudar a cultura das unidades de informação passando de impositiva para uma cultura de participação. Essa nova visão parte do princípio de que os interagentes são também "coautores de boa parte da informação que circula nos mais diversos canais, colaborando em seus processos de criação e fluxo, especialmente no ambiente digital".

\section{A BIBLIOTERAPIA E O FOCO NO INTERAGENTE}

Se o indivíduo interage e transforma o meio em que vive ele é considerado uma célula ativa nesse grande organismo chamado sociedade, seja ela definida como da Informação ou do Conhecimento. Nesse sentido, é importante que existam pesquisas na área da Ciência da Informação que tratem desse sujeito, não simplesmente como mero usuário ou um dado, mas como um ser que atribui significados, que participa do mundo da vida, infere valores, produz ciência, informação e conhecimento.

Dentro desse contexto, o tema da Biblioterapia se encaixa perfeitamente nessa visão mais ampla das pesquisas em Ciência da Informação. Esse campo começou a ser explorado principalmente na área da saúde, mas sempre contou com o envolvimento de profissionais da informação, em especial os bibliotecários, mesmo que atuando como coadjuvantes no processo. Desta 
forma, o conceito de Biblioterapia nasce como um campo interdisciplinar que agrega profissionais de diversas áreas, inclusive da Ciência da Informação.

Sob o ponto de vista etimológico, a palavra Biblioterapia não deixa muitas dúvidas em relação ao seu significado. Resultado da junção de dois termos gregos, biblion (livro) e therapeia (terapia) o significado da palavra é entendido como terapia por meio dos livros. Por mais que esse termo cause certo estranhamento em algumas pessoas, a Biblioterapia não é uma novidade. Como afirma Ouaknin $(1996,27)$, "quanto mais longe remontarmos na história, mais encontraremos esta intuição da virtude terapêutica do livro e da narrativa".

Historicamente a Biblioterapia sempre esteve presente em diversos espaços a fim de promover algum tipo de benefício para o ser humano. Ao longo do tempo, a leitura terapêutica foi introduzida em hospitais, especialmente logo após a segunda guerra mundial, e em outros espaços como escolas, presídios, asilos e orfanatos.

Apesar de ser comumente associada a doentes e ser muito difundida em ambientes hospitalares, a Biblioterapia serve para todas as pessoas, não só para aquelas que foram diagnosticadas com algum tipo de doença.

[...] ela é válida tanto para o doente (internado ou não em um hospital), como para o ser que não percebe, de fato, como seu equilíbrio está comprometido, mas sente que lhe falta algo essa falta indica que não está são e, portanto, necessita recuperar o equilíbrio, pois somente o ser são está completo. Nos dois casos a leitura se configura como um tratamento, uma terapia, ou seja, uma maneira de promover a saúde (CALDIN, 2010, p. 61)

No processo da aplicação da terapia através da leitura é fundamental o conhecimento da ferramenta que é o livro e a familiaridade com o texto escrito. Mas sob o ponto de vista de Caldin (2010), muito mais do que simples terapia por meio dos livros ou da leitura, a Biblioterapia configura-se como o cuidado com o ser por meio das histórias, sejam elas lidas, narradas ou dramatizadas. Nesse sentido, os profissionais que estão envolvidos nesse tipo de atividade precisam adotar uma postura diferenciada e acima de tudo ter "consciência do potencial terapêutico da leitura." (CALDIN, 2005, p. 21). 
Para alguns pesquisadores, a prática da terapia por meio dos livros obedece regras de aplicação, ou seja, possui uma fórmula, ou uma receita a ser seguida para que seja eficaz.

Segundo Pinto (2005), por exemplo, a Biblioterapia é uma prática de vivências multidisciplinares que precisa necessariamente do acompanhamento de um terapeuta. Para a autora, é imprescindível que a Biblioterapia seja praticada por um bibliotecário com formação terapêutica, psicólogo, psicoterapeuta, psiquiatra, ou por um bibliotecário em uma atividade conjunta com algum destes profissionais.

Nesse caso, a autora reduz a Biblioterapia a uma "prática empírica" (PINTO, 2005, p. 40), uma Ciência, que pressupõe caminhos bem delineados para se chegar a um resultado satisfatório a partir da razão pura e do intelecto. A exemplo de Pinto, outros autores também enquadram a Biblioterapia dentro do campo das Ciências e quase sempre a associam a práticas de saúde, chegando mesmo a reduzi-la a uma atividade coadjuvante no tratamento de pessoas hospitalizadas.

Apesar de vários autores defenderem a prática da Biblioterapia associada a métodos e técnicas psicoterapêuticas, Silva (2005) aponta que o tema é estudado majoritariamente por profissionais da área de Biblioteconomia no Brasil, ou seja, dentro do campo da Ciência da Informação. De acordo com o autor, $70 \%$ da produção documental sobre o tema publicada no período de 1975 a 2004 no Brasil é de autoria de profissionais da área de Biblioteconomia. Desta forma, é possível afirmar que no Brasil a Biblioterapia tem sido aplicada e estudada em grande escala no do campo da Ciência da Informação.

Entretanto, mesmo na Biblioteconomia há divergências sobre o conceito e a prática da Biblioterapia. Se por um lado, pesquisadores a exemplo de Pinto, consideram-na uma prática empírica, por outro há quem defenda que está mais pautada no universo da sensibilidade, das emoções. Não existe, portanto, um caminho ou um mapa exato que conduza o profissional durante a aplicação da terapia por meio dos livros.

Como defende Caldin (2010), a Biblioterapia é um campo onde prevalece, sobretudo, a visão humana sobre o ser em contrapartida a uma 
visão especializada. Nesse contexto, a autora defende que, independente da forma, seus aplicadores devem prezar por alguns aspectos subjetivos, a exemplo da fala cortês, do olhar gentil e do toque carinhoso. Pois, segundo ela, esses são elementos altamente terapêuticos.

Essa visão traz à tona um aspecto mais humano dentro do campo de atuação dos profissionais da informação, mais especificamente dos bibliotecários. Esse ponto de vista coloca a Biblioterapia como uma área da Ciência da Informação que leva em conta o sujeito como peça chave, apesar da ferramenta, o livro, ser o componente fundamental que fará a conexão do indivíduo consigo mesmo e o instrumento que conduzirá o processo terapêutico.

Nesse processo, é muito clara a posição do interagente, como bem delineou Corrêa (2014) - na medida em que a construção do processo e resultado dependem da ação do indivíduo que é foco da Biblioterapia. Essa interação dentro do processo biblioterapêutico se dá num âmbito consciente ou inconsciente.

Ao ler ou ouvir histórias o ser humano responde a estímulos provocados no seu consciente e no seu inconsciente que agem, ou não, de forma positiva em seu ser, gerando reflexões ou mesmo mudanças significativas. Isso ocorre devido aos elementos terapêuticos contidos nos textos de ficção que provocam reações como a catarse, a identificação e a introspecção.

Se o envolvimento com a história produzir a catarse, a identificação ou a introspecção (não necessariamente concomitante ou sucedâneas), tal história cumpriu o propósito terapêutico, mesmo que isso não fique visível ou não seja facilmente detectado. De fato, no mias das vezes, apenas o atingido sabe em que medida o texto permitiu-lhe trabalhar as emoções, ativar a imaginação ou fazer uma reflexão (CALDIN, 2010, p. 121).

Explicitando: a catarse é uma reação inconsciente do indivíduo e é considerada uma espécie de purgação, purificação, limpeza profunda seguida de um estado de leveza que gera o sentimento de alívio. O mais importante nesse processo é que o indivíduo chegue ao equilíbrio, à harmonia. Advoga 
Caldin (2010, p. 24): "Ao tirar de nós um peso insuportável de ser carregado, a catarse alivia o mal que interrompe o fluxo da saúde."

Outro aspecto terapêutico que também pode ser vivenciado com a Biblioterapia é a identificação, que vem a ser um processo inconsciente de apropriação do outro, ou seja, dos atributos dos personagens ficcionais. Nesse processo, afirma Caldin (2010) que o indivíduo toma emprestado a identidade e a força do personagem para enfrentar seus problemas e buscar soluções, o que é extremamente terapêutico.

Um terceiro aspecto benéfico na leitura terapêutica é a introspecção. Diferente da catarse e da identificação, a introspecção se caracteriza como um processo consciente - o indivíduo examina seus pensamentos e atitudes com o intuito de mudança de comportamento, ou então de uma aceitação de si e do outro. Para Caldin (2010), a leitura oferece um parâmetro para exame do comportamento do receptor do texto a partir do comportamento dos personagens.

A partir dessa análise consciente o sujeito atribui significados para a história e consegue fazer uma ponte entre o que foi lido ou ouvido com a sua própria história de vida. No entanto, os significados são múltiplos e variam principalmente de acordo com a idade e o momento que a pessoa está vivendo.

Todo esse processo proporcionado pela prática da Biblioterapia está vinculado com codificação de informação e pela atribuição de significados com o fim de produzir conhecimento, típico dos estudos da Ciência da Informação. No entanto, o que se percebe no processo biblioterapêutico é o foco no indivíduo, que assume o papel de interagente, atribuindo seus próprios significados, dando vazão à subjetividade.

A prática da Biblioterapia também preza o compartilhamento entre aqueles que estão envolvidos no processo. Ao compartilhar suas experiências e emoções durante as atividades biblioterapêuticas o indivíduo interage com os demais e consegue dessa forma buscar suporte no exterior para nomear aquilo que o incomoda no seu interior. Segundo Ouaknin (1996, p.34) as histórias ajudam as pessoas a "passar do sensível ao inteligível". 
A Biblioterapia, afirma Caldin (2010, p. 126), "utiliza a fala como coadjuvante terapêutico na forma do diálogo que o texto literário enseja." Essa fala, essa pluralidade de vozes, garante que o processo biblioterapêutico seja, também, facilitador da intersubjetividade, pois os interagentes trocam ideias, experiências, repartem alegrias e tristezas.

Falar sobre Biblioterapia é, portanto, uma forma de levantar uma reflexão sobre os aspectos humano e social da Ciência da Informação, a fim de que de fato esta possa alicerçar-se como ciência pós-moderna.

Além disso, vale destacar que o caráter interdisciplinar da Biblioterapia sempre esteve na raiz do seu surgimento. Sendo assim o diálogo entre esta e a Filosofia e a Psicologia ocorre de forma natural e contribui para ampliar os horizontes da Ciência da Informação.

\section{BIBLIOTERAPIA - $O$ QUIASMA ENTRE A CIÊNCIA DA INFORMAÇÃO, A FILOSOFIA E A PSICOLOGIA}

Cabe lembrar que a filosofia é mãe de todas as ciências (CHAUÍ, 2010) e é definida como a utilização do conhecimento válido em benefício do ser humano (ABBAGNANO, 2003).

Assim, surgida na Grécia, a filosofia investigou a origem do mundo, as transformações da natureza, as questões humanas, o conhecimento de forma sistematizada, a física, a ética e a teologia; na Idade Média as ideias filosóficas gregas foram mescladas com a cultura muçulmana, dando destaque à medicina, psicologia e metafísica; no Renascimento valorizou-se o ser humano; a filosofia Moderna - chamada de Grande racionalismo - priorizou a razão e escamoteou a fé; no lluminismo a biologia, a política e a economia mereceram destaque; a filosofia contemporânea (século XIX aos nossos dias) presenciou o progresso científico e o despertar da Pós Modernidade (CHAUÍ, 2010).

Nessa rápida passagem pelos meandros da origem e do desenvolvimento da filosofia, resgata-se o pensamento de Maurice MerleauPonty, professor, filósofo, estudioso da fenomenologia de Edmund Husserl. 
Tal escolha dá-se pelo seu comprometimento com o texto literário e pela criação da expressão "fala falante." Para Merleau-Ponty (2002) existem duas linguagens: a fala falada e a fala falante; a primeira se compõe de signos estabelecidos com significações partilhadas pelos membros de uma língua, a segunda é a alteração e transfiguração de significados produzindo uma nova significação - que acontece pela leitura de um livro.

Ora, a fala falante, criadora, é objeto de estudo da Biblioterapia. A terapia por meio da leitura só acontece quando o leitor infere novos sentidos ao texto literário, quando permite a invasão do personagem ficcional na sua vida, quando desarma-se de preconceitos e aceita a alteridade, quando, desprevenido, esquece-se das dores físicas e emocionais e vivencia uma catarse, uma purgação.

Paralelo aos estudos sobre a linguagem Merleau-Ponty (2003) debruçou-se sobre questionamentos sobre o corpo, ou seja, como o corpo percebe e é percebido. Para tanto, valeu-se da psicologia da Gestalt e das ideias psicanalíticas de Freud.

Segundo Merleau-Ponty (2002) o diálogo só é possível porque o ser humano é carne. Como tal, vê e ouve o outro: "O outro, a meus olhos, está portanto sempre à margem do que vejo e ouço, está a meu lado ou atrás de mim, não está nesse lugar que meu olhar esmaga e esvazia de todo 'interior'” pois "Todo outro é um outro eu mesmo" (MERLEAU-PONTY, 2002, p.168, grifo do autor).

É essa percepção do outro como fazendo parte do meu corpo que permite o diálogo, a Inter corporeidade, a intersubjetividade, a coexistência o descentramento, - tão caros à Biblioterapia. O filósofo indaga: "Temos ou não temos um corpo, isto é, um objeto de pensamento permanente, mas com uma carne que sofre quando ferida, e mãos que apalpam?" (MERLEAU-PONTY, 2003, p. 133).

Essa apalpação - mãos que se tocam e se sentem tocadas - mostram o ser humano como sujeito e como objeto. Como sujeito, percebe-se e percebe os outros. Como objeto, é passível de estudos. Nesse sentido, o corpo vidente e sentiente vivencia o quiasma (entrelaçamento): 
[...] meu corpo vidente subtende esse corpo visível e todos os visíveis com ele. Há reciprocamente inserção e entrelaçamento de um no outro. Ou melhor, se renunciarmos, como é preciso ainda uma vez, ao pensamento por planos e perspectivas, há dois círculos, ou dois turbilhões, ou duas esferas concêntricas quando vivo ingenuamente $\mathrm{e}$, desde que me interrogue, levemente descentrados um no outro.... (MERLEAU-PONTY, 2003, p. 135).

Esse entrelaçamento do corpo com o mundo e as coisas visíveis (entre elas o corpo do outro) permite inferir o quiasma entre as ciências. Assim é que serão apresentadas as ideias de um psicólogo polonês - Wiktor Czernianin. Esse passeio pela psicologia fortalecerá os aspectos interdisciplinares da Ciência da Informação.

Czernianin (2013) prioriza a poesia no processo catártico e apresenta no seu texto: a) como a poesia surge; b) como a poesia cura - catarse; c) a catarse na poesia terapia aplicada para fins terapêuticos; d) a catarse na poesia terapia aplicada para "purificação" moral; e) a catarse na poesia terapia aplicada como experiência mística; f) a catarse na poesia terapia aplicada para a experiência estética; f) a catarse na poesia terapia aplicada como prazer hedonista.

Ao resgatar o surgimento do poema no inconsciente - emoções borbulhantes que aos serem expressas em palavras ocasionam alívio, Czernianin (2013) lembra que todas as artes surgiram na Grécia, entre elas, a poesia - e à expressão artística era concedida o poder de liberação emocional, entendida como catarse.

Explicando como a poesia cura Czernianin (2013) vale-se dos conceitos aristotélicos de catarse - purificação das emoções no espectador da tragédia, que se sensibiliza com as agruras do herói no desenrolar do enredo.

Cabe aqui um aparte: a compaixão e o medo, advindos da tragédia grega, eram considerados benéficos justamente por se passar no universo ficcional, não ocasionado dano físico ao povo. Assim, aliviados, os espectadores voltariam à sua vida normal com a agressividade matizada e diluída, em um estado e equilíbrio mental. 
$\mathrm{Na}$ aplicação da poesia terapia, Czernianin (2013) enfoca a catarse como libertadora das experiências penosas do leitor, uma vez que este último realiza uma equivalência com as experiências do autor do poema.

Dessa feita, há aqui também um entrelaçamento de vivências, de intersubjetividades, de diálogo entre o poeta e seu leitor. Ambos purgam suas emoções no lirismo e na metáfora que o texto poético enseja e prioriza.

Entendendo moralidade como uma avaliação das atitudes do ser humano, Czernianin (2013, p.29, tradução nossa) vê a purificação moral na poesia como "uma transgressão que significa ultrapassar essa atmosfera: é um movimento do mau para bom precisamente."

Assim, a bom e o mau (e o bem e o mal) excluem-se mutuamente, pois não há harmonia entre eles - e o psicólogo defende o papel da religiosidade como catártico - chama a atenção, em especial, para a poesia sagrada, nomeando-a de poema-oração. Nessa mesma linha de pensamento, considera a experiência mística também catártica, obtida pelo êxtase, uma conexão entre Deus e o devoto (CZERNIANIN, 2013).

Com relação à experiência estética, entrelaça poesia com música (principalmente para atender ao público jovem), pois advoga que ambas despertam emoções (produtoras da catarse); nesse sentido, prioriza o sentido da audição.

Apresenta três estágios da experiência estética musical: o primeiro acontece quando brotam os sentimentos e emoção e envolvimento com a música; o segundo, quando tal envolvimento se fortalece ocasionando uma comunhão entre ouvinte e canção; o terceiro estágio se caracteriza pelo sentimento de calma e passividade - o prazer contemplativo (CZERNIANIN, 2008 apud CZERNIANIN, 2013).

No tocante à articulação da catarse na poesia terapia como prazer hedonista, busca apoio em Freud e nos psicanalistas freudianos para defender a poesia erótica.

Entende o erotismo registrado em forma de poema por pessoas com deficiências físicas como terapêutico, pois permite a expressão de prazer 
aliada à sexualidade e ao amor como uma revolta à sociedade ou ao seu próprio corpo (CZERNIANIN, 2013).

Como observado, o trabalho de Czernianin adota (inadvertidamente?) um alinhamento com as ideias de Merleau-Ponty no que tange à percepção pelo corpo, à produção de novos significados, ao diálogo com o texto.

E nesses meandros filosóficos e psicológicos a Biblioterapia se encontra intricada. Impossível não perceber os paralelos existentes. $\mathrm{Na}$ sua interdisciplinaridade, a Ciência da Informação abraça a Filosofia e a Psicologia.

\section{CONCLUSÃO}

São inúmeros os entrelaçamentos possíveis entre as ciências. Neste artigo mostramos o quiasma entre a Ciência da Informação, a Filosofia e a Psicologia, tendo como fio condutor a Biblioterapia.

Relembrar esses cruzamentos e as inúmeras possibilidades de diálogos que podem ser conduzidos é sempre pertinente. Principalmente quando se trata da Ciência da Informação, que, apesar de ser interdisciplinar, ainda exclui algumas formas de conhecimento em que o indivíduo suplanta a máquina.

A Filosofia e a Psicologia estão entre essas formas de conhecimento em que o sujeito e a sua subjetividade estão presentes, o que ocorre, também, na Biblioterapia. No momento em que o leitor ou ouvinte infere sentidos ao texto literário (através da fala falante definida por Merleau-Ponty), e com seu corpo dá vida aos sentimentos e emoções vivenciados na leitura (a catarse, por exemplo), ele assume o papel de interagente, de célula viva, no processo informacional.

Assumindo o caráter de Ciência Pós Moderna, abraçando a interdisciplinaridade e considerando o ser humano de forma holística, com sua subjetividade e complexidade, a Ciência da Informação abre caminhos para novos quiasmas de pesquisa. Relembrar que o ser humano é vivo, tem sua singularidade e interage nesse universo onde a informação passou a dominar, é, sem dúvida, uma trilha a ser explorada.

A Biblioterapia se presta a esse mister, pois tem o sujeito como foco principal. E abre caminho para que o ser humano possa ser compreendido 
Carla Souza, Clarice Fortkamp Caldin

Biblioterapia: o quiasma entre as ciências

enquanto ser que sente, que fala e que interage com o outro e com o mundo à sua volta - preocupações, também da Filosofia e da Psicologia.

\section{REFERÊNCIAS}

ARAÚJO, Carlos Alberto Ávila. Ciência da Informação como Ciência Social. Ciência da Informação, Brasília, v. 32, n. 3, p. 21-27, set./dez. 2003. Disponível em:

<http://revista.ibict.br/cienciadainformacao/index.php/ciinf/article/view/29/26>. Acesso em: 10 mar. 2015

BORKO, Harold. Information science: what is this? American Documentation. 1968. Disponível em:

$<$ https://www.marilia.unesp.br/Home/Instituicao/Docentes/EdbertoFerneda/k--artigo-01.pdf>. Acesso em jun. 2015.

BURCH, Sally. Sociedade da informação /sociedade do conhecimento. 2005. Disponível em: <http://vecam.org/archives/article699.html>

Acesso em 15 mar. 2015.

CALDIN, Clarice Fortkamp. Biblioterapia: um cuidado com o ser. São Paulo: Porto de Idéias, 2010.

CORREAA, Elisa C.D. Usuário, não! Interagente. Proposta de um novo termo para um novo tempo. Encontros Bibli, Florianópolis, v. 19, n. 41, p. 23-40, dez. 2014. Disponível em:

$<$ https://periodicos.ufsc.br/index.php/eb/article/view/15182924.2014v19n41p23/28292>. Acesso em: 02 jun. 2015.

CZERNIANIN, Wiktor. Catharsis in poetry therapy. Polish: Journal of Applied Psychology, Wrocław. v. 12, n. 2, p. 25-38, 2013. Disponível em:

<http://www.pjap.psychologia.uni.wroc.pl/sites/default/files/Czernianin.pdf>. Acesso em set. 2015.

LE COADIC, Yves François. A ciência da informação. 2. ed. Brasília: Briquet de Lemos, 2004.

MERLEAU-PONTY. Maurice. A prosa do mundo. Tradução de Paulo Neves. São Paulo: Cosac \& Naif, 2002.

MERLEAU-PONTY. Maurice. O visível e o invisível. Tradução de José Artur Gianotti; Armando Mora d' Oliveira. 4. ed. São Paulo: Perspectiva, 2003.

OUAKNIN, Marc-Alain. Biblioterapia. São Paulo: Loyola, 1996. 
PINTO, Virgínia Bentes. A biblioterapia como campo de atuação para o bibliotecário. Transinformação, Campinas, v. 17, n. 1, p. 31-43, jan./abr. 2005. Disponível em: <http://www.scielo.br/scielo.php?script=sci arttext\&pid=S010337862005000100003\&lng=en\&nrm=iso >. Acesso em 10 fev. 2015.

SARACEVIC, Tefko. Ciência da Informação: origem, evolução e relações. Perspectivas em Ciência da Informação, Belo Horizonte, v. 1, n.1, p. 41-62, jan./jun. 1996. Disponível em: $<$ http://portaldeperiodicos.eci.ufmg.br/index.php/pci/article/view/235>. Acesso em: 20 jun. 2015.

SILVA, Alexandre Magno da. Características da produção documental sobre biblioterapia no Brasil. 2005. 121 f. Dissertação (Mestrado em Psicologia) - Universidade Federal de Santa Catarina, Florianópolis, 2005. Disponível em: <http://www.tede.ufsc.br/teses/PPSI0170.pdf>. Acesso em: 20 ago. 2015.

\title{
Title
}

Bibliotherapy: the chiasmus between the sciences

\begin{abstract}
:
Introduction: This paper presents the Bibliotherapy, well known as the terapeutic function of reading, as an interlocution between the Information Science, Philosophy and Psycology. Based on the concept of interdisciplinarity, inherent of post-modern sciences, it strengthens the comprehension of human being in the complex Knowledge Society.

Objective: It presents a possible crossing between Information Science, Philosophy and Psycology refered to the concepts and ideais about Bibliotherapy.

Methodology: It was based in a exploratory, qualitative and bibliographic research. The literature review pointed the firsts studies in Information Science; presented the Bibliotherapy focused in the interactant; showed the possibles crossings between Information Science, Philosophy and Psycology through Bibliotherapy.

Results: The break of paradigms in Information Science - that enphasizes economics and tecnologics factors - and the interactant seen as the central character of informations's process allows researchs focused in the human being.

Conclusions: The sharing ideias between Information Science, Philosophy and Psycology allows a more acurate understanding about Bibliotherapy especially related to: dialog, intercorporeity, intersubjectivity, catarsis.
\end{abstract}

Keywords: Bibliotherapy. Information Science. Interdisciplinarity. Philosophy. Psycology.

\section{Titulo}

La biblioterapia: el quiasma de las ciencias 


\section{Resumen:}

Introducción: El artículo presenta la biblioterapia, entendida como función terapéutica de la lectura, como interlocución entre Ciencia de la Información, Filosofía y Psicología. Se parte del concepto de interdisciplinaridad, propio de las ciencias postmodernas, que fortalecen la comprensión del ser humano en la compleja sociedad del conocimiento.

Objetivo: Presentar el entrecruzamiento de la Ciencia de la Información, Filosofía y Psicología basado en conceptos e ideas sobre la biblioterapia.

Metodología: La investigación fue exploratoria, cualitativa y bibliográfica. La revisión de la literatura apuntó los primeros estudios en la Ciencia de la Información; presentó la biblioterapia con foco en el interagente; mostró las posibilidades de cruce entre La Ciencia de la Información, filosofía y psicología a partir de la perspectiva de la Biblioterapia.

Resultados: El quiebre de paradigmas en la Ciencia de la Información - primacía de los factores económicos y tecnológicos - y la inserción del interagente como fin primero y último de las preocupaciones, han permitido estudios direccionados al ser humano como personaje central del proceso informacional.

Conclusiones: Compartir ideas entre la Ciencia de la Información, Filosofía y Psicología permite un entendimiento más minucioso de la Biblioterapia en especial sobre: diálogo, intercorporeidad, intersubjetividad, catarsis.

Palabras clave: Biblioterapia. Ciencia de la Información. Interdisciplinaridad. Filosofía. Filosofía.

Recebido em: 27.04.2016

Aceito em: 09.11.2017 